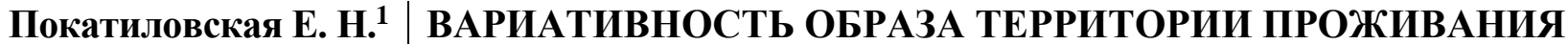 Шибаева Л. В. ${ }^{2}$ У ГОРОЖАН С РАЗНОЙ СОЦИАЛЬНОЙ ПОЗИЦИЕЙ
}

1) Сургутский государственный педагогический университет, 10/2, ул. 50 лет ВЛКСМ, г. Сургут, 628417, Россия

E-mail: elizabet3462@mail.ru

2) Сургутский государственный педагогический университет, 10/2, ул. 50 лет ВЛКСМ, г. Сургут, 628417, Россия

E-mail: shibaeva2003@gmail.com

Аннотация: Представлены результаты исследования эмпирических проявлений позиции субъекта территориального сообщества в контексте социальнопсихологического подхода к проблеме изучения жизнеспособности города. В статье сопоставляются когнитивные характеристики образа города и двора в представлениях жителей разных по возрасту, с разным отношением к городу как месту постоянного проживания. Выявлено различие категорий описания городского и дворового сообщества жителей с разной социальной позицией (социальных лидеров и пассивных горожан). На основе применения метода репертуарных решеток Дж. Келли дана характеристика различий между простотой / дифференцированностью семантического описания города как места постоянного проживания и эмоциональной окрашенностью дескрипторов. Выявленные различия в семантике образа двора у жителей многоквартирного дома подтверждают эти различия при оценке респондентами состояний безопасности и комфорта жизни в условиях дворового сообщества. Представлены эмпирические данные об особенностях оценки состояний безопасности и комфорта жителями, с разной мерой психологической готовности к позиции субъекта межличностных отношений в дворовом сообществе многоквартирного дома. Результаты исследования позволили характеризовать вариативность восприятия образа города и двора жителями с разной социальной позицией и детализировать вариации представлений горожан о безопасности и комфорте проживания во дворе многоэтажного дома, типичного для городского сообщества. Психологической основой разнообразия социальных позиций членов городского и дворового сообщества выступает большая или меньшая выраженность территориальной идентичности. Подчеркнута перспективность изучения своеобразия образа города и двора у жителей с разной социальной позицией в городском сообществе.

Ключевые слова: жизнеспособность города; субъект территориального сообщества; территориальная идентичность; дескрипторы оценки города и двора; безопасность территориального сообщества. 
E. N. Pokatilovskaia ${ }^{1}$

L. V. Shibaeva ${ }^{2}$

\title{
VARIABILITY OF THE IMAGE OF THE TERRITORY
OF RESIDENCE AMONG CITIZENS WITH DIFFERENT \\ VARIABILITY OF THE IMAGE OF THE TERRITORY
OF RESIDENCE AMONG CITIZENS WITH DIFFERENT SOCIAL POSITIONS
}

Surgut State Pedagogical University, 10/2 50 years of VLKSM St., Surgut, 628417, Russia

E-mail: elizabet3462@mail.ru

Surgut State Pedagogical University, 10/2 50 years of VLKSM St., Surgut, 628417, Russia

E-mail: shibaeva2003@gmail.com

\begin{abstract}
The article presents the results of the study of empirical manifestations of the position of the subject of the territorial community in the context of the sociopsychological approach to the problem of studying the viability of the city. The authors compare the cognitive characteristics of the image of the city and the courtyard in the representations of residents of different ages, with different attitudes to the city as a place of permanent residence. The difference in categories of descriptions of cities and the courtyard community of residents with different social positions (social and passive townspeople) is revealed. Based on the application of the method of repertory grids by J. Kelly, the authors describe the characteristics of the differences between the simplicity / differentiation of the semantic description of the city as a place of permanent residence and the emotional color of descriptors. The revealed differences in the semantics of the yard image among residents of an apartment building confirm these differences when assessing the respondents' safety and comfort conditions in a courtyard community. Empirical data are presented on the features of assessing the states of security and comfort by residents, with different measures of psychological readiness for the position of the subject of interpersonal relations in the courtyard community of a block of flats. The results of the study made it possible to characterize the variability in the perception of the image of the city and the yard by residents with different social positions and to detail the variations of the representations of citizens about the safety and comfort of living in the courtyard of a block of flats typical of the urban community. The greater or lesser degree of territorial identity is the psychological basis of the diversity of social positions of members of the urban and courtyard community. The perspectives of studying the specificity of the image of the city and the yard among residents with different social positions in the urban community are underlined.
\end{abstract}

Key words: city vitality; the subject of the territorial community; territorial identity; descriptors of city and yard estimation; security of territorial community.

Введение. Вызовы динамичной социально-экономической действительности ставят перед современными психологами методологические, теоретические и прикладные проблемы, требующие категориальных и исследовательских подходов, аналогов которых трудно найти в классической и академической науке.

К одной из таких проблем относится исследование жизнеспособности моногородов и поселений как системного субъект- объектного свойства, подразумевающего изучение многогранных структурных и функциональных связей $[2,11,15]$.

Реализация такого исследовательского подхода может осуществляться относительно различных по масштабу территориальных жизненных пространств: региона, города, района города, двора, подъезда.

Анализ работ, выполняемых в русле возникающих социально-психологических исследований этого направления, дает воз- 
можность наметить такой ракурс изучения, который позволяет рассматривать жизнеспособность города как продукт деятельности социально активных горожан и организаций, готовых взять на себя ответственность за судьбу поселений и быть активно вовлеченными в решение местных проблем разного масштаба. Лидерская активность горожан, рассматриваемая как фактор позитивной динамики кризисных поселений, подчеркивается в ряде отечественных и зарубежных исследований $[4,6,11,12,13$, $14,15]$.

Однако категориальный строй для характеристики психологического своеобразия «картины мира» горожан с активной лидерской позицией при их сопоставлении с «картиной мира» и оценочными дескрипторами пассивных жителей («городских пассажиров») остается мало изученным.

Целью исследования выступал поиск эмпирических проявлений - дескрипторов жителей, идентифицирующихся с городом и полагающих в нем свое будущее, как месте постоянного проживания, испытывающих состояние «социальных лидеров» или занимающих позицию «городских пассажиров».

Теоретическая основа и методология нашего исследования опиралась на категориальный строй, ориентированный на применение категории «субъект жизнедеятельности» для обозначения человека, способного организовать свою жизнь на основе осознанного самоопределения, которая найдет свое выражение в качестве территориальной идентичности. Применение понятия «субъект» осуществлялось нами с опорой на традиции отечественных исследователей, таких как К.А Абульханова-Славская, С.Л Рубинштейн, В.А Татенко, Э.В. Сайко, В.И. Слободчиков. При всем разнообразии интерпретаций к пониманию позиции субъекта, мы считаем возможным и необходимым анализировать такой подход, при котором она соотносится с особенностями территориальной идентичности. Содержательно территориальная идентичность выступает результатом процесса осознанного самоопределения, отождествления индивида со своей малой родиной и, прежде всего, с ценностями, разделяемыми локальным территориальным сообществом. Это переживаемые эмоционально и осознаваемые рационально ценности локальной общности, которые формируют осознание территориальной принадлежности индивида и выражаются в характерном «алфавите» оценочных суждений - дескрипторов.

Объектом исследования в нашей работе выступали когнитивные, эмоциональные и деятельные проявления позиции горожанина, как субъекта территориального сообщества с разным отношением к городу как месту постоянного проживания.

Предмет исследования: специфика дескрипторов, применяемых для оценки места проживания жителями с выраженной позицией субъекта территориального сообщества в отличие от дескрипторов жителей с низким уровнем такой позиции.

Гипотеза исследования состояла в предположении, что позиция субъекта территориального сообщества обусловлена территориальной идентичностью, которая найдет свое эмпирическое проявление в своеобразии суждений - дескрипторов, выражающих отношение к территориальному сообществу и готовности деятельно влиять на его состояние.

Трудности изучения территориальной идентичности (как в глобальном масштабе региона, города, так и локальном - двора) создаются вследствие сложного набора оснований, на которые ориентируется человек. Ее изучение предполагает выявление множества аспектов в качестве тех оснований, которые проявляются в дескрипторах описания городского пространства, городского сообщества, в выражении у жителей сопричастности к локальному сообществу, проживающему вместе с ним на одной территории [7, 14].

Идентичность, оформленная на основе осознанной ориентировки на существенные социально-экономические, производственно-технологические, культурно-исторические качества поселения выступает в качестве результата самоопределения человека, которого правомерно обозначить, как инициативного субъекта, осознанно плани- 
рующего свое будущее и будущее своей семьи в данном месте проживания.

Исследование состояло из двух частей.

Материалом в первой части исследовании выступали особенности оценочных суждений, которыми пользуются группы респондентов при характеристике города как постоянного места проживания, полученные методом репертуарных решеток Дж. Келли с последующим кластерным и факторным анализом.

Материалом во второй части исследования выступали данные о позиции жителей дворового сообщества многоквартирного дома и переживания ими состояний безопасности и комфорта, выявленные на основе комплекса анкет.

Результаты исследования. Задача первой части исследования состояла в выявлении своеобразия образа города в представлениях жителей с разной социальной позицией, в разных возрастных группах при характеристике города, как постоянного места проживания.

На первом - предварительном - этапе этой части исследования нами характеризовалось отношение жителей к городу на основе анкеты, предложенной жителям с разным стажем проживания в городе. Выборка составила 116 человек. Из них пожилого возраста - 35 респондентов, 30 респондентов среднего возраста и 51 респондент из числа молодежи.

На основе анкеты были выделены следующие позиции:

1. Житель с инициативной, активной позицией субъекта городского сообщества. Типичный представитель этой группы выделяет г. Сургут как перспективный; предоставляющий возможность для образования, карьеры; дает развернутое обоснование ответов на вопросы о символе города; любимых местах в городе; выражает готовность к решению проблем города, которые он выделяет, предлагает направления решений. К этой группе оказалось возможным отнести: респондентов пожилого возраста - $44 \%$, респондентов среднего возраста - 35\%, peспондентов из числа молодежи $-21 \%$.
2. Житель с невыраженной позицией субъекта в городском сообществе, не идентифицирующийся с ним, но использующий его ресурсы для достижения финансового благополучия. В эту группу вошли, в основном, жители среднего возраста, устроенные в градообразующие предприятия; нейтральные по отношению к культурным и образовательным ресурсам города; подчеркивающие определенные признаки дискомфорта и делегирующие разрешение проблем администрации, властям. К ним относились: респонденты пожилого возраста - 34\%, peспонденты среднего возраста - 38\%, peспонденты из числа молодежи - $28 \%$.

3. Жители с аморфной оценкой ресурсов города для экономического благополучия и неопределенным отношением к городскому сообществу. Для них характерна «диффузная» территориальной идентичность, нивелирующая их принадлежность к данному городскому сообществу. Из них: респонденты пожилого возраста - $24 \%$, peспонденты среднего возраста - 35\%, респонденты из числа молодежи - $41 \%$.

Детализация образа города у жителей с разной социальной позицией была осуществлена на основе индивидуального исследования группы выпускников вузов г. Сургута (15 человек в возрасте 23-27 лет) с разным отношением к городу.

В исследовании применялось полустандартизированное интервью, которое было направлено на выявление отношения к городу, как постоянному месту проживания. Выяснялась выраженность желания уехать из города, желания остаться в городе и фиксировалась по условной шкале степень болезненности этой проблемы для респондента. Было зафиксировано разделение участников на три подгруппы по данным этой методики: выражающих желание остаться, выражающих желание уехать и колеблющихся (по пять человек в каждой подгруппе).

Далее применялся метод репертуарных решеток, предложенный Дж. Келли с последующей обработкой методами кластерного и факторного анализа [9]. 
Для сопоставления различий в семантике «образа города как психологического пространства жизни» применялась репертуарная решетка (РР), включающая следующие 19 элементов: 1. Я как житель Сургута; 2. Сердечный город; 3. Город для интересной работы; 4. Сургут; 5. Город музеев и театров; 6. Сонный город; 7. Опасный город; 8. Безопасный город; 9. Житель идеального города; 10. Перспективный город; 11. Город не для меня; 12. Угрожающий город; 13. Привлекательный город; 14. Город для образования; 15. Город для души; 16. Перспективный город; 17. Успешный человек; 18. Счастливый человек; 19. Город без будущего.

Как известно, метод применения РР предполагает сопоставление элементов так, чтобы два из них были объединены и отделены от третьего «лишнего». Основания различий должны были выделены респондентами и составляли перечень «конструктов», т.е., тех дескрипторов, на основе которых человек характеризовал город. Осуществлялся контент-анализ конструктов, позволяющих выявить содержание значений, сквозь призму которых оценивались разные аспекты жизни в городе. Данные обрабатывались на основе применения кластерного анализа, для того, чтобы зафиксировать различия в семантической характеристике «образа города» в выделенных группах респондентов.

Результаты кластерного анализа позволили выявить две отдельные группировки семантических характеристик, которые включают элементы позитивного и негативного описания города. В выборке в целом, основание для самоопределения респондентов с позицией «счастливый горожанин» дистанцировалось как от кластера с позитивными параметрами, так и негативными. Это свидетельствует о том, что преобладает неопределенность в отнесении жителями себя к оптимальному состоянию «счастливого горожанина». Неопределенность и низкий уровень осознанности самоопределения были выявлены и по данным факторного анализа. Его результаты позволили выделить то, что мера разнообразия конструктов настолько низка, что конструкты не образовали даже двух факторов. Микроанализ индивидуальных данных в группе респондентов с низким уровнем осознанности самоопределения свидетельствует о том, что ими акцентируется один из параметров города (негативный или позитивный), который перевешивает порой разнообразные параметры оценки города. Так, фактор «Дружба» может быть противопоставлен параметрам неблагоприятного климата, фактор «безопасность/опасность» жизни в городе - группе признаков экономического благополучия.

Результаты кластерного и факторного анализа позволили подчеркнуть то, что жители с пассивной и неопределенной позицией характеризуются простотой алфавита конструктов и неопределенностью включения себя как жителя в кластер признаков благополучного или менее благополучного города.

У жителей с активной социальной позицией наибольшую нагрузку (64\% до 81\% общей дисперсии) имели факторы с позитивным звучанием «Развитая экономика» $(0,958)$; «Разнообразный рынок труда» $(0,935)$; «Успешный» $(0,948)$; «Город детства» $(0,915)$; «Хорошее образование» $(0,900)$; «Молодежный» $(0,929)$; «Много музеев и театров» $(0,928)$.

Проведенное исследование позволило характеризовать группу респондентов, испытывающих состояние неопределенности как мало ориентированных в характеристиках города, имеющих размытое отношение к существенным характеристикам оценки перспективности города в сфере образования, досуга, карьеры. Представители выборки с выраженной социальной позицией характеризовались более дифференцированным семантическим описанием города, имеющим эмоционально позитивную окрашенность.

Задачей второй части исследования выступало изучение дескрипторов, применяемых при оценке таких параметров образа территориальной среды, как безопасность, комфорт проживания во дворе города, или альтернативного образа - опасного и дискомфортного. 
Респондентами выступали жители многоквартирного дома. Эмпирическая гипотеза состояла в том, что для жителей с высоким уровнем территориальной идентичности и выраженными установками проявлять себя в позиции субъекта межличностных отношений в сообществе соседей будут характерны дескрипторы, описывающие двор многоэтажного дома (совместного пространства жизни) как комфортный, безопасный.

Выборка составила 50 человек, из них к группе молодежи относились 30 человек, группа среднего и пожилого возраста - 20 человек. Применялся следующий состав методик: анкета для выявления готовности жителей в позиции соседей вести переговоры о таких сферах взаимодействия как: возможность наладить приветливые отношения с соседями, возможность преодоления конфликтности с соседями, возможность договориться о режиме тишины, возможность договориться об аккуратности общих мест пользования; методика, выявляющая степень опасений жителей по поводу возможности оказаться жертвой дискомфортного и опасного поведения со стороны соседей (опросник «тип ролевой виктимности» [8]); методика, позволяющая зафиксировать условный балл степени идентичности с сообществом соседей во дворе и условный балл степени социальной вовлеченности в жизнь города.

Анализ результатов анкеты позволил сопоставить меру готовности взаимодействия, выраженную жителями разных возрастных групп, представленную в средних баллах в таблице 1.

Таблица 1

\section{Средние показатели межличностных отношений с соседями} в двух разных возрастных группах

Average indicators of interpersonal relations with neighbors in two different age groups

\begin{tabular}{|l|c|c|}
\hline \multicolumn{1}{|c|}{$\begin{array}{c}\text { Характеристики отношений с соседями } \\
\text { и чувство сообщества }\end{array}$} & $\begin{array}{c}\text { Молодые } \\
\text { респонденты }\end{array}$ & $\begin{array}{c}\text { Респонденты } \\
\text { среднего и зрело- } \\
\text { го возраста }\end{array}$ \\
\hline $\begin{array}{l}\text { Средний балл оценки возможности наладить } \\
\text { приветливые отношения с соседями }\end{array}$ & 3,37 & 6 \\
\hline $\begin{array}{l}\text { Средний балл оценки возможности преодоления } \\
\text { конфликтности с соседями }\end{array}$ & 3,70 & 5,65 \\
\hline $\begin{array}{l}\text { Средний балл оценки возможности договориться } \\
\text { о режиме тишины }\end{array}$ & 4,90 & 5,4 \\
\hline $\begin{array}{l}\text { Средний балл оценки возможности договориться } \\
\text { об аккуратности общих мест пользования }\end{array}$ & 4,23 \\
\hline $\begin{array}{l}\text { Средний бал социальной вовлеченности в город- } \\
\text { ские проблемы }\end{array}$ & 5,37 & 6,01 \\
\hline
\end{tabular}

При сопоставлении средних показателей в выборке 30-ти молодых респондентов и 20-ти респондентов среднего и зрелого возраста было выявлено, что респонденты среднего и зрелого возраста больше готовы договариваться с соседями о комфортном физическом и психологическом пространстве жизни и выстраивать добрососедские отношения. Важно подчеркнуть, что именно эти жители выразили и высокую готовность соучаствовать в разрешении городских проблем вне дворового благоустройства.

Для детализации полученных результатов производился анализ данных полученных по дополнительным методикам. Одна из них позволяла оценивать условный балл степени идентичности с сообществом соседей по двору. Другая методика - выяв- 
ляла степень опасений жителей по поводу возможности оказаться жертвой дискомфортного и опасного поведения со стороны соседей [8].
Соотношение результатов в двух группах респондентов представлено в таблице 2.

Средние баллы оценки состояния безопасности во дворе и оценки причастности к сообществу соседей в двух разных возрастных группах

Table 2

Average scores for assessing the state of security in the yard and assessing the involvement of neighbors in the community in two different age groups

\begin{tabular}{|c|c|c|}
\hline $\begin{array}{c}\text { Характеристики отношений с соседями и иден- } \\
\text { тичности с сообществом }\end{array}$ & $\begin{array}{l}\text { Молодые ре- } \\
\text { спонденты }\end{array}$ & $\begin{array}{c}\text { Респонденты сред- } \\
\text { него и зрелого воз- } \\
\text { раста }\end{array}$ \\
\hline $\begin{array}{l}\text { Средний балл оценки отношений с соседями и } \\
\text { чувство сообщества }\end{array}$ & 4,23 & 5,95 \\
\hline $\begin{array}{l}\text { Средний бал показателя состояния безопасности } \\
\text { во дворе }\end{array}$ & 5,2 & 6,85 \\
\hline
\end{tabular}

Выявлена статистическая значимость различий по t-критерию Стьюдента оценки отношений с соседями и идентичности с сообществом в двух разных возрастных группах при $\mathrm{p} \leq 0.01(\mathrm{t}=2.7)$. Значимость показателей состояния безопасности во дворе в двух разных возрастных группах при $\mathrm{p} \leq 0.01(\mathrm{t}=4.3)$.

При сопоставлении средних балов общего показателя состояния безопасности во дворе и среднего балла оценки идентичности с территориальным сообществом выявилось различие в двух возрастных выборках. Было выявлено, что респонденты среднего и зрелого возраста, выстраивая добрососедские отношения, чувствуют себя более безопасно, комфортно в сообществе соседей. Данные, полученные в молодежной вы-

борке и выборке респондентов среднего возраста, позволили зафиксировать, что представители с низкими балами оценки безопасности характеризуются низкими и средними баллами показателей сопричастности, общности с соседями (24 респондентов с высокими балами, 26 респондентов с низкими балами оценки безопасности во дворе). Эти данные представлены в таблице 3.

Таблица 3

Средние показатели оценки безопасности во дворе, вовлеченности в жизнь города в соотношении с показателями методики «Тип ролевой виктимности»

Average indicators of security in the yard, involvement in the life of the city in relation to the indicators of the method "Type of role victimism"

\begin{tabular}{|l|c|c|c|}
\hline $\begin{array}{c}\text { Респонденты с разными ба- } \\
\text { лами общего показателя со- } \\
\text { стояния безопасности } \\
\text { во дворе }\end{array}$ & $\begin{array}{c}\text { Средний } \\
\text { бал по } \\
\text { шкале РВ }\end{array}$ & $\begin{array}{c}\text { Средний бал обще- } \\
\text { го показателя со- } \\
\text { стояния безопасно- } \\
\text { сти во дворе }\end{array}$ & $\begin{array}{c}\text { Средний бал общего } \\
\text { показателя социаль- } \\
\text { ной вовлеченности } \\
\text { в жизнь города }\end{array}$ \\
\hline $\begin{array}{l}\text { Респонденты с высокими бала- } \\
\text { ми общего показателя состоя- } \\
\text { ния безопасности во дворе }\end{array}$ & 5,25 & 7,42 & 6,23 \\
\hline $\begin{array}{l}\text { Респонденты с низкими балами } \\
\text { общего показателя состояний } \\
\text { безопасности во дворе }\end{array}$ & 6,67 & 3,75 & 4,97 \\
\hline
\end{tabular}


Выявлена статистическая значимость различий по t-критерию Стьюдента соотношений среднего балла по шкале РВ и среднего балла показателя состояния безопасности во дворе в выборке респондентов с высокими балами общего показателя состояния безопасности во дворе при $\mathrm{p} \leq 0.01(\mathrm{t}=4.2)$. Значимость соотношения среднего балла по шкале РВ и среднего балла показателя состояния безопасности во дворе в выборке респондентов с низкими балами показателя состояний безопасности во дворе при $\mathrm{p} \leq 0.01(\mathrm{t}=4)$. Значимость соотношения среднего балла показателя состояния безопасности во дворе и среднего бала. общего показателя социальной вовлеченности в жизнь города в выборке респондентов с низкими балами показателя состояний безопасности во дворе при $\mathrm{p} \leq 0.01 \mathrm{t}$ (3.3). Значимость соотношения среднего балла показателя состояния безопасности во дворе и среднего бала общего показателя социальной вовлеченности в жизнь города в выборке респондентов с высокими балами общего показателя состояния безопасности во дворе при $\mathrm{p} \leq 0.01(\mathrm{t}=4.7)$.

Сопоставление данных позволило сформулировать вывод о том, что респонденты с высокими балами показателя безопасности во дворе в меньшей мере опасаются стать жертвой случайных обстоятельств и берут большую ответственность за происходящее в их жизни, чем респонденты с низкими балами оценки безопасности во дворе.

Исследование позволило выявить, что представители выборки, оценивающие двор как безопасный, характеризовались большей выраженностью позиции субъекта переговоров с соседями. Низкая готовность к переговорам с соседями соответствовала более высоким показателям оказаться жертвой непредвиденных обстоятельств и дискомфортного поведения соседей.

Результаты исследований позволили подтвердить отличие дескрипторов, характеризующих безопасность и комфорт у жителей с высоким уровнем территориальной идентичности, которая выступает основанием для проявления инициативной субъектной позиции жителей не только в локальном сообществе, но и сообществе города. Это проявлялось в оценочных суждениях о возможности выстраивать продуктивные отношения с соседями и готовности брать на себя ответственность в разрешении проблем развития города, участвовать в общественно значимых мероприятиях.

Таким образом, решение задач второй части исследования позволила нам сфокусировать внимание на отношении жителей к дворовому сообществу и оценке «безопасного пространства жизни», связанного с готовностью выстраивать инициативные от- ношения с соседями в позиции субъекта взаимодействия и общения. Изучение жителей со стороны выраженности позиции субъекта межличностных отношений в дворовом сообществе и ее связи с разной оценкой состояний безопасности и комфорта, позволило наметить перспективы проблемы изучения особенностей восприятия жителями своих ресурсов в организации безопасного пространства жизни.

Две части проведенного нами исследования позволили подтвердить положение о том, что социальная позиция горожан, для которых характерна активная субъектная позиция, находит свое выражение в особенностях дескрипторов, применяемых для оценки города и оценки состояний безопасности и комфорта в дворовом сообществе соседей.

Это нашло свое проявление в спектре эмпирических показателей.

Выявились различия оценки отношений с соседями и идентичности с ними, состоящие из оценки возможности: наладить приветливые отношения с соседями, преодолевать конфликты, договариваться о режиме тишины, об аккуратности общих мест пользования; позволили выявить различия в возрастных выборках молодых респондентов и респондентов среднего и зрелого возраста. Эти различия характеризуют респондентов среднего и зрелого возраста, как готовых к сотрудничеству с соседями, способных выстраивать добрососедские отношения, основанные на взаимовыручке и помощи, учитывать пожелания соседей и создавать партнерские отношения для комфортного физического и психологического пространства жизни. 
Рассмотрение показателей оценки безопасности во дворе позволило выявить взаимосвязь его с показателями оценки отношений с соседями и идентичности с сообществом в выборках молодых респондентов и респондентов среднего и зрелого возраста. Показатели по методике, позволяющей выявить оценки опасности стать жертвой дискомфорта и/или опасности, подтвердили наше предположение о том, что респонденты с высокими баллами безопасности во дворе в большей мере верят в свои силы при выстраивании комфортного физического и психологического пространства жизни. Они в меньшей мере опасаются стать жертвой случайных обстоятельств, берут большую ответственность за происходящее в их жизни, чем респонденты с низкими баллами общего показателя безопасности.

Проведенное исследование позволит в дальнейшем детализировать теоретический конструкт, позволяющий характеризовать многогранность позиции субъекта городского и дворового сообщества с выраженной территориальной идентичностью. Намечены определенные параметры, важные для описания позиции жителя как субъекта, способного к осознанному территориальному самоопределению и выбору места проживания, готового принимать ответственность за состояние безопасности и комфорта.

В исследовании получены результаты, которые позволили характеризовать вариативность восприятия образа города и двора жителями с разной социальной позицией, детализировать вариации представлений горожан о безопасности и комфорте проживания во дворе многоэтажного дома, типичного для данного города и состава городского сообщества. Психологической основой разнообразия социальных позиций членов дворового и городского сообщества выступает большая или меньшая выраженность территориальной идентичности. Проведение дальнейшего исследования в этой области будет ориентировано на продолжение изучения проявлений городской идентичности во всем многообразии ее когнитивных, эмоциональных и поведенческих аспектов.
Информация о конфликте интересов: авторы не имеют конфликта интересов для декларации.

Conflicts of Interest: the authors have no conflict of interests to declare.

\section{Список литературы}

1. Абульханова-Славская К.А. Проблема определения субъекта в психологии // Субъект действия, взаимодействия, познания: психологические, философские, социокультурные аспекты. Москва-Воронеж. 2001. С. 35-47.

2. Мехова А.А. Чернов А.В. Комплексный подход к безопасности (на примере программы «Здоровый город») // Безопасность жизнедеятельности. 2011. №5. С. 19-28.

3. Наумова Н.Ф. Социологические и психологические аспекты целенаправленного поведения. М.: Наука, 1988. 250 с.

4. Нуйкина Е. Социальная жизнеспособность северного города в современных условиях: лидерство и низовая активность населения/ Известия Коми научного центра УрО РАН. Выпуск 3(23). Сыктывкар. 2015. С. 156-160.

5. Рубинштейн С.Л. Принцип детерминизма и проблема личности // Принципы и пути развития психологии. М.: Педагогика. 1959.С. 116-137.

6. Смолова Л.В. Безопасность городской среды в восприятии жителей с позиции психологии взаимодействия с окружающей средой// Обретение Астаной столичного статуса: Сборник докладов Второй международной научной конференции. Астана: Елорда. 2009. С.53-62.

7. Татенко В.А. Психология в субъектном измерении. К.: Видавничий центр «Просвита», 1996. $404 \mathrm{c}$.

8. Одинцова М.А., Радчикова Н.П. Разработка и стандартизация опросника «Тип ролевой виктимности» // Известия ПГПУ им. В.Г. Белинского. 2012. № 28. С. 1303-1310.

9. Покатиловская Е.Н., Шибаева Л.В., Хохлова Н.И. Применение метода репертуарных решеток для исследования особенностей восприятия города как психологического пространства жителей с разной мерой идентичности // Северный регион: наука, образование, культура. 2016. № 2(34). C 162-168.

10.Штейнбах Х.Э. Еленский В.И. Психология жизненного пространства. СПб.: Речь, 2004. $239 \mathrm{c}$.

11.Bolotova A. and Stammler F. (2010). "How the North became home. Attachment to Place among Industrial Migrants in Murmansk region. 
Migration in the Circumpolar North: Issues and Contexts", Edmonton, Canada Canadian Circumpolar Institute Press, 193-220.

12.Gans H.J. (1968). "Criteria for neighborhood viability" New York, Columbia University.

13.Keczmerski J. and Sorter B. (1984). "A community viability indicator for determining comprehensive planning policy", Social Indicators Research 14 (2), 195-203.

14.Nuykina E. (2014). "Making a viable city: visions, strategies and practices", Doctoral dissertation, University of Vienna.

15.Schoenberg, S.P. and Rosenbaum, P.L. (1980). "Neighborhoods that work: Sources forviability in the inner city", New Brunswick, Rutgers University Press.

\section{References}

1. Abulkhanova-Slavskaya, K.A. (2001), "The problem of determining the subject in psychology", Sub"yekt deystviya, vzaimodeystviya, poznaniya: psikhologicheskiye, filosofskiye, sotsiokul'turnyye aspekty, 35-47.

2. Mekhova, A.A. and Chernov, A.V. (2011), "Comprehensive approach to safety (on the example of the program "Healthy City")", Bezopasnost' zhiznedeyatel'nosti, 5, 19-28.

3. Naumova, N.F. (1988), Sotsiologicheskiye $i$ psikhologicheskiye aspekty tselenapravlennogo povedeniya [Sociological and psychological aspects of purposeful behavior], Moscow, Russia.

4. Nuykina, E. (2015), "Social viability of the northern city in modern conditions: leadership and grass-roots activity of the population", Izvestiya Komi nauchnogo tsentra UrO RAN, 3 (23), 156160.

5. Rubinshtein, S.L. (1959), Printsip determinizma i problema lichnost [Principle of determinism and the problem of personality], Pedagogika, Moscow, Russia.

6. Smolova, L.V. (2009), "Security of the urban environment in the perception of residents from the standpoint of the psychology of interaction with the environment". Obreteniye Astanoy stolichnogo statusa: Sbornik dokladov Vtoroy mezhdunarodnoy nauchnoy konferentsii, Astana, Kazakhstan, 53-62.

7. Tatenko, V.A. (1996), Psikhologiya $v$ sub"yektnom izmerenii [Psychology in the Subject Dimension], Vidavnichy center Prosvita, Kiev, Ukraine.
8. Odintsova, M.A. and Radchikova, N.P. (2012), "Development and standardization of the questionnaire «Type of role victimism»", Izvestiya PGPU im. V.G. Belinskogo, 28, 1303-1310.

9. Pokatilovskaya, E.N., Shibaeva, LV and Khokhlova, N.I. (2016), "Application of the method of repertory grids to study the features of the perception of the city as a psychological space of residents with different measure of identity", Severnyy region: nauka, obrazovaniye, kul'tura, 2 (34), 162168.

10. Steinbach, H.E. and Yelensky V.I. (2004), Psikhologiya zhiznennogo prostranstva [Psychology of living space], SPb: Speech, St. Petersburg, Russia

11. Bolotova, A. and Stammler, F. (2010), "How the North became home. Attachment to Place among Industrial Migrants in Murmansk region. Migration in the Circumpolar North: Issues and Contexts", Canadian Circumpolar Institute Press, Edmonton, Canada, 193-220

12.Gans, H.J. (1968), "Criteria for neighborhood viability”, Columbia University, New York, USA.

13.Keczmerski, J. and Sorter, B. (1984), "A community viability indicator for determining comprehensive planning policy", Social Indicators Research 14(2), 195-203

14.Nuykina, E. (2014). "Making a viable city: visions, strategies and practices", Doctoral dissertation, University of Vienna, Austria.

15.Schoenberg, S.P. and Rosenbaum, P.L. (1980), "Neighborhoods that work: Sources for viability in the inner city", New Brunswick, Rutgers University Press, USA.

\section{Данные авторов:}

Покатиловская Елизавета Николаевна, аспирантка кафедры психологии

Шибаева Людмила Васильевна, доктор психологических наук, профессор кафедры психологии

\section{About the authors:}

Elizaveta Nikolaevna Pokatilovskaia, Postgraduate Student, Department of Psychology Lyudlmila Vasilyevna Shibaeva, Doctor of Psychology, Professor, Department of Psychology 